\title{
PENILAIAN ASET WARISAN BUDAYA MENGGUNAKAN MARKET APPEAL-ROBUSTICITY MATRIX
}

\author{
(ASSESSMENT OF CULTURAL HERITAGE ASSETS \\ USING MARKET APPEAL-ROBUSTICITY MATRIX)
}

\author{
Titis Wiji Ahyati, Riza Firmansyah*, Devi Roza K. Kausar \\ Fakultas Pariwisata, Universitas Pancasila Srengseng Sawah, \\ Jagakarsa Jakarta Selatan 12640, Indonesia \\ *rfirmansyah@univpancasila.ac.id
}

\begin{abstract}
Market Appeal Robusticity Matrix is an effective assessment of cultural heritage assets to evaluate the potential market appeal and management of cultural heritage tourism (robusticity). It is important to determine appropriate policies and frameworks for better planning decisions in the future. This study aims to describe the preservation of cultural heritage at the Puppet Museum and analyze the valuation of cultural heritage assets at the Puppet Museum, Jakarta Old Town using Market Appeal-Robusticity Matrix. The research design used is qualitative analysis of Market Appeal-Robusticity Matrix. The results of this study have described the preservation of cultural heritage in the Museum, protection is done through maintenance and restoration, development is done by adding value to cultural heritage buildings by making it a Puppet Museum and the use of cultural heritage buildings is done by considering the interests of religion, social, culture and society. Preservation has been well implemented and adapted to the regulations of Law number 11 of 2010 concerning Cultural Heritage. Whereas the valuation of cultural heritage assets yields the value of the market attractiveness of the High Puppet Museum with a score of 51 and the resilience value of the building of the Medium Puppet Museum with a score of 40. In this assessment the Puppet Museum is in the "Al" category which means high market attractiveness and moderate resilience. Keywords: Market Appeal Robusticity Matrix, valuation of cultural heritage assets, preservation.
\end{abstract}

\begin{abstract}
Abstrak
Market Appeal Robusticity Matrix merupakan penilaian aset warisan budaya yang efektif untuk mengevaluasi potensi daya tarik pasar dan pengelolaan wisata warisan budaya. Hal ini penting untuk menentukan kebijakan dan kerangka kerja yang sesuai untuk keputusan perencanaan yang lebih baik di masa depan. Penelitian ini bertujuan untuk mendeskripsikan pelestarian warisan budaya di Museum Wayang dan menganalisis penilaian aset warisan budaya di Museum Wayang Kotatua Jakarta menggunakan Market Appeal-Robusticity Matrix. Desain penelitian yang digunakan adalah kualitatif dengan analisa Market Appeal-Robusticity Matrix. Hasil dari penelitian ini telah mendeskripsikan pelestarian warisan budaya di Museum, perlindungan dilakukan melalui perawatan dan pemugaran, pengembangan dilakukan dengan menambah nilai pada bangunan cagar budaya dengan menjadikannya sebagai Museum Wayang dan pemanfaatan bangunan cagar budaya dilakukan dengan mempertimbangkan kepentingan bagi agama, sosial, budaya dan masyarakat. Pelestarian sudah dijalankan dengan baik dan disesuaikan dengan peraturan Undang-undang nomor 11 tahun 2010 tentang Cagar Budaya. Sedangkan penilaian aset warisan budaya menghasilkan nilai daya tarik pasar Museum Wayang tinggi dengan skor 51 dan nilai ketahanan bangunan Museum Wayang sedang dengan skor 40. Dalam penilaian ini Museum Wayang berada di kategori "A1" yang artinya daya tarik pasar tinggi dan ketahanan sedang.
\end{abstract}

Kata kunci: Market Appeal Robusticity Matrix, penilaian aset warisan budaya, pelestarian. 


\section{PENDAHULUAN}

Keberagaman suku bangsa dan kekayaan alam menjadi potensi daya tarik pariwisata yang menarik di Indonesia, hal tersebut memicu munculnya beragam jenis pariwisata yang tersedia di Indonesia. Salah satu jenis pariwisata yang banyak diminati wisatawan di Indonesia adalah cultural tourism atau pariwisata budaya. Pariwisata budaya merupakan jenis pariwisata yang menawarkan kebudayaan yang berupa atraksi budaya baik yang bersifat tangible maupun intangible, juga yang bersifat living culture (budaya yang masih berlanjut) dan cultural heritage (warisan budaya masa lalu), sebagai daya tarik utama untuk menarik kunjungan wisatawan. Wisata ini dilakukan atas dasar keinginan untuk memperluas pandangan hidup seseorang dengan jalan mengadakan kunjungan atau peninjauan ke tempat lain mempelajari keadaan suatu masyarakat, kebiasaan dan adat istiadat masyarakat suatu daerah, cara hidup, budaya maupun seni yang terdapat pada masyarakat suatu daerah tertentu (Pendit 2002). Salah satu wisata budaya Indonesia yang menjadi warisan budaya atau cagar budaya yang telah dikembangkan menjadi pariwisata adalah Museum Wayang di Kawasan Kotatua Jakarta.

Museum menurut International Council of Museums (ICOM 1974), adalah lembaga permanen yang tidak mencari keuntungan dalam melayani kebutuhan masyarakat dan perkembangannya terbuka untuk umum, yang mengakuisisi, melestarikan, meneliti, mengkomunikasikan dan memamerkan untuk tujuan studi, pendidikan dan kesenangan, sebagai bukti nyata manusia dan lingkungannya.

Hal ini sesuai dengan Peraturan Pemerintah Republik Indonesia Nomor 19 Tahun 1995 Tentang Museum, definisi museum adalah lembaga, tempat penyimpanan, perawatan, pengamanan, dan pemanfaatan benda-benda bukti materiil hasil budaya manusia serta alam dan lingkungannya guna menunjang upaya perlindungan dan pelestarian kekayaan budaya bangsa dan bertujuan untuk melestarikan dan memanfaatkan warisan budaya dalam rangka menunjang pengembangan kebudayaan nasional melalui upaya penyimpanan, perawatan, pengamanan, dan pemanfaatan serta mempunyai tugas pengkajian, pendidikan, dan kesenangan. Oleh karena itu, positioning museum sangat penting, selain sebagai tempat penyimpanan juga dapat melestarikan benda bukti materiil hasil budaya manusia, alam dan lingkungannya. Hal ini sesuai dengan Stamenković dan Jakšić (2013), bahwa fungsi museum penting dalam pelestarian karena dapat mewarisakan warisan budaya ke generasi selanjutnya, dapat dijadikan sumber pendapatan dan menciptakan lapangan kerja baru.

Museum wayang yang terletak di Kawasan Kotatua Jakarta memiliki sekitar 6,373 koleksi berupa wayang, topeng, patung, lukisan dan alat musik yang berasal dari dalam maupun luar negeri. Sebagai atraksi pariwisata, Museum Wayang yang merupakan bangunan tua bekas gereja yang didirikan pada tahun 1640 juga menawarkan keindahan dan kekokohan arsitektur peninggalan Belanda. Museum Wayang merupakan salah satu atraksi wisata di Kawasan Kotatua yang dikembangkan sebagai produk pariwisata akan tetapi, Museum Wayang masih memerlukan suatu evaluasi yang dapat menjadi acuan pengembangan. Berdasarkan hasil wawancara peneliti dengan pengelola Museum Wayang, bangunan Museum Wayang memerlukan perawatan ekstra karena dijadikan sebagai atraksi pariwisata. Dengan adanya permasalahan tersebut, maka penting bagi pengelola untuk menganalisis penilaian aset warisan budaya Market Appeal-Robusticity Matrix (Cros dan McKercher, 2015). Melalui penilaian Market Appeal-Robusticity Matrix, akan diketahui seberapa besar Museum Wayang menarik wisatawan dan ketahanannya dalam menampung wisatawan sehingga pengelola dapat menerapkan kebijakan dan strategi yang tepat untuk meningatkan wisatawan.

Menurut Rapidah, dkk (2018) Penggunaan Market Appeal-Robusticity Matrix dinilai efektif untuk mengevaluasi penilaian potensi wisata warisan budaya karena mempertimbangkan dua hal penting dari industri pariwisata dan manajemennya yaitu, aset yang menjadi daya tarik dan kemampuanya dalam mengatasi pengunjung. Penilaian ini penting untuk melindungi aset warisan budaya dengan kebijakan dan kerangka kerja yang sesuai untuk keputusan perencanaan yang lebih baik di masa depan. peneliti akan mendeskripsikan pelestarian 
warisan budaya wayang di Museum Wayang dan menganalisis penilaian aset warisan budaya wayang di Museum Wayang yang dijadikan daya tarik wisata agar aset dapat dikelola pemeliharaan dan pelestariannya secara baik serta dapat menarik wisatawan untuk berkunjung.

\section{METODE}

Penelitian ini menggunakan pendekatan kuantitatif dan Market Appeal-Robusticity Matrix digunakan untuk menilai aset warisan budaya di Museum Wayang. Lokasi penelitian ini adalah di Museum Wayang Kawasan Kotatua Jakarta. Lokasi ini adalah salah satu aset warisan budaya atau cagar budaya di Indonesia yang telah ditetapkan oleh Menteri dan Gubernur dan dijadikankan sebagai atraksi pariwisata. Sehingga, penelitian mengenai penilaian aset warisan budaya ini sangat sesuai dengan kondisi Museum Wayang Kotatua Jakarta.

Metode pengumpulan data pada penelitian ini diperoleh dari data primer dan data sekunder. Data primer diperoleh melalui wawancara terstruktur dan penyebaran kuesioner kepada informan. Penentuan jumlah sampel, menggunakan teknik Purposive Sampling yaitu pemilihan sekelompok sampel yang memiliki kriteria yang sesuai dengan tujuan penelitian ini.
Informan tersebut diantaranya Unit Pengelola Museum Wayang, Unit Pengelola Kotatua dan pengunjung Museum Wayang yang dinilai dapat mengerti dan memahami kondisi Museum Wayang. Data sekunder yang diperoleh dari dokumentasi, buku, jurnal penelitian, penelitianpenelitian sebelumnya yang berkaitan, dan literasi lainnya yang dijadikan acuan penelitian. Metode pengumpulan data pada penelitian ini yaitu dengan observasi, wawancara, kuesioner dan dokumentasi.

Teknik analisis data pada penelitian ini menggunakan Analisis data penelitian ini dilakukan secara kualitatif menggunakan rumus ordinal dan Market Appeal-Robusticity Matrix. Rumus ordinal digunakan untuk menghitung hasil kuesioner yang menggunakan skala likert dan dikonversikan ke dalam interval. Dengan penghitungan skor tertinggi, skor terendah, rumus interval, range dan penghitungan indeks untuk menentukan kategori hasil kuesioner.

Market Appeal-Robusticity Matrix digunakan untuk penilaian aset warisan budaya. Setiap aset yang dipilih secara terperinci dan dinilai sesuai dengan masing-masing sub-indikator (Tabel 1) dengan menggunakan sistem poin skala yang digunakan oleh beberapa peneliti. Penelitian ini menggunakan skala penilaian hasil modifikasi du Cros yang juga digunakan dalam Li dan Lo (2004).

Tabel 1. Sub-indikator pariwisata warisan budaya dan nilai peringkat

\begin{tabular}{|c|c|c|c|c|}
\hline \multirow{2}{*}{ No } & \multicolumn{4}{|c|}{ SEKTOR PARIWISATA } \\
\hline & \multicolumn{4}{|c|}{ Market Appeal (Daya Tarik Pasar) } \\
\hline \multirow{2}{*}{1.} & \multicolumn{4}{|l|}{ Suasana dan keadaan } \\
\hline & Sangat Baik (5) & Baik (4) & Cukup Baik (2-3) & Tidak Baik (0-1) \\
\hline \multirow{2}{*}{2.} & \multicolumn{4}{|l|}{ Terkenal di luar daerah setempat } \\
\hline & Sangat Setuju (5) & Setuju (4) & Cukup Setuju (2-3) & Tidak Setuju $(0-1)$ \\
\hline \multirow{2}{*}{3.} & \multicolumn{4}{|c|}{ Ikon nasional atau Simbol nasional } \\
\hline & Sangat Setuju (5) & Setuju (4) & Cukup Setuju (1-3) & Tidak Setuju (0) \\
\hline \multirow{2}{*}{4.} & \multicolumn{4}{|c|}{ Menceritakan sebuah kisah yang bagus } \\
\hline & Sangat Setuju (5) & Setuju (4) & Cukup Setuju (1-3) & Tidak Setuju (0) \\
\hline \multirow{2}{*}{5.} & \multicolumn{4}{|c|}{ Memiliki ciri khas yang membedakannya dari atraksi disekitar Kawasan Kotatua } \\
\hline & Sangat Setuju (5) & Setuju (4) & Cukup Setuju (2-3) & Tidak Setuju (0-1) \\
\hline \multirow{2}{*}{6.} & \multicolumn{4}{|c|}{ Menawarkan kegiatan khusus yang juga menarik (seperti festival, olahraga, workshop) } \\
\hline & Sangat Setuju (5) & Setuju (4) & Cukup Setuju (2-3) & Tidak Setuju (0-1) \\
\hline No & \multicolumn{4}{|c|}{ Market Appeal (Daya Tarik Pasar) } \\
\hline \multirow{2}{*}{7.} & \multicolumn{4}{|c|}{ Melengkapi atraksi wisata lain disekitar Kawasan Kotatua } \\
\hline & Sangat Setuju (5) & Setuju (4) & Cukup Setuju (1-3) & Tidak Setuju (0) \\
\hline \multirow{2}{*}{8.} & \multicolumn{4}{|c|}{ Museum Wayang merupakan aset warisan budaya yang penting secara lokal, regional, nasional, atau internasiona } \\
\hline & Sangat Setuju (5) & Setuju (4) & Cukup Setuju (2-3) & Tidak Setuju (0-1) \\
\hline \multirow{2}{*}{9.} & \multicolumn{4}{|c|}{ Museum Wayang menggambarkan keunikan suatu tradisi budaya } \\
\hline & Sangat Setuju (5) & Setuju (4) & Cukup Setuju (2-3) & Tidak Setuju(0-1) \\
\hline
\end{tabular}




\begin{tabular}{|c|c|c|c|c|}
\hline \multicolumn{5}{|c|}{ Product Design Needs (Nilai Pariwisata) } \\
\hline \multirow{2}{*}{10.} & \multicolumn{4}{|c|}{ Tersedianya informasi yang sesuai dan memadai } \\
\hline & Sangat Setuju (4) & Setuju (3) & Cukup Setuju (1-2) & Tidak Setuju (0) \\
\hline \multirow{2}{*}{11.} & \multicolumn{4}{|c|}{ Dapat diakses dengan mudah menggunakan transportasi } \\
\hline & Sangat Setuju (3) & Setuju (2) & Cukup Setuju (1) & Tidak Setuju (0) \\
\hline \multirow{2}{*}{12.} & \multicolumn{4}{|c|}{ Dekat dengan atraksi wisata budaya yang lain } \\
\hline & Sangat Setuju (3) & Setuju (2) & Cukup Setuju (1) & Tidak Setuju (0) \\
\hline \multirow{2}{*}{13.} & \multicolumn{4}{|c|}{ Keadaan amenitas (fasilitas) yang ada di Museum Wayang, termasuk toilet, parkir, jalur, mushola } \\
\hline & Sangat Baik (5) & Baik (3-4) & Cukup Baik (1-2) & Tidak Baik (0) \\
\hline \multicolumn{5}{|c|}{ PENGELOLAAN WARISAN BUDAYA } \\
\hline \multicolumn{5}{|c|}{ Cultural Significance (Nilai Budaya) } \\
\hline \multirow{2}{*}{14.} & \multicolumn{4}{|c|}{ Nilai keindahan (termasuk nilai arsitektur dalam hal bangunan) yang terdapat di Museum Wayang } \\
\hline & Tinggi (2) & Sedang (1) & Rendah (0) & \\
\hline \multirow{2}{*}{15.} & \multicolumn{4}{|c|}{ Nilai historis/sejarah yang terdapat di Museum Wayang } \\
\hline & Tinggi (2) & Sedang (1) & Rendah (0) & \\
\hline \multirow{2}{*}{16.} & \multicolumn{4}{|c|}{ Nilai pendidikan yang terdapat di Museum Wayang } \\
\hline & Tinggi (2) & Sedang (1) & Rendah (0) & \\
\hline \multirow{2}{*}{17.} & \multicolumn{4}{|c|}{ Nilai sosial yang terdapat di Museum Wayang } \\
\hline & Tinggi (2) & Sedang (1) & Rendah (0) & \\
\hline \multirow{2}{*}{18.} & \multicolumn{4}{|c|}{ Nilai ilmiah/adanya potensi penelitian yang terdapat di Museum Wayang } \\
\hline & Tinggi (2) & Sedang (1) & Rendah (0) & \\
\hline \multirow{2}{*}{19.} & \multicolumn{4}{|c|}{ Museum Wayang merupakan jenis aset warisan budaya yang langka atau umum di tempat tujuan } \\
\hline & Unik (3) & Langka (2) & Umum (1) & \\
\hline & \multicolumn{4}{|c|}{ Museum Wayang menjadi contoh wisata warisan budaya yang baik di Kawasan Kotatua } \\
\hline 20. & Sangat Setuju (4) & Setuju (3) & Cukup Setuju (2) & Tidak Setuju (1) \\
\hline & & Robustic & Iilai Fisik) & \\
\hline 21 & Kondisi kerapuhan bangunan & luseum Wayang & & \\
\hline 21. & Sangat Rapuh (1) & Rapuh (2-3) & Tidak Rapuh (4) & \\
\hline 22 & Kondisi perbaikan bangunan $\mathrm{I}$ & useum Wayang & & \\
\hline $2 L$. & Sangat Baik (4) & Baik (2-3) & Cukup Baik (1) & Tidak Baik (0) \\
\hline 23 & Perencanaan pengelolaan dan & ebijakan yang ber & di Museum Wayang & \\
\hline 23. & Sangat Baik (5) & Baik (4) & Cukup Baik (1-3) & Tidak Baik (0) \\
\hline 24 & Pemantauan dan pemeliharaan & perawatan) rutin & unan Museum Wayang & \\
\hline 24. & Sangat Baik (5) & Baik (3-4) & Cukup Baik (1-2) & Tidak Baik $(0)$ \\
\hline & Adanya potensi kerjasama ber & lanjutan para per & la Museum Wayang & \\
\hline 25. & Sangat Baik (5) & Baik (3-4) & Cukup Baik (1-2) & Tidak Baik (0) \\
\hline & Adanya kemungkinan dampak & egatif (karena kun & an yang tinggi di Muse & g) terhadap: \\
\hline & a. Struktur bangunan Museur & Wayang & & \\
\hline 26. & Tinggi (5) & Sedang (2-4) & Rendah (1) & \\
\hline & b. Gaya hidup dan tradisi buc & ya masyarakat se & & \\
\hline & Tinggi (5) & Sedang (2-4) & Rendah (1) & \\
\hline & Adanya kemungkinan dampak $\mathrm{n}$ & gatif (karena perub & dalam pengembangan $\mathrm{N}$ & ayang) pada: \\
\hline & a. Struktur bangunan Museur & Wayang & & \\
\hline 27. & Tinggi (5) & Sedang (2-4) & Rendah (1) & \\
\hline & b. Gaya hidup dan tradisi buc & ya masyarakat se & & \\
\hline & Tinggi (5) & Sedang (2-4) & Rendah (1) & \\
\hline
\end{tabular}

\section{Sumber: du Cros dalam Li dan Lo (2004)}

Sektor pariwisata diwakili oleh dua subindikator: daya tarik pasar dari aset budaya dan faktor-faktor penting untuk merancang produk pariwisata. Sektor manajemen aset budaya juga mengandung dua sub-indikator: kepentingan dan ketahanan budaya. Sub-indikator dinilai dengan nilai 0 hingga 5 , tetapi indikator tertentu memiliki peringkat nilai yang berbeda. Selanjutnya jumlah poin tersebut digolongkan dalam kategori: daya tarik pasar/kekokohan rendah dengan skala 0-20, daya tarik/kekokohan sedang dengan skala 20-40, atau daya tarik/ kekokohan tinggi 
dengan skala 41-60. Setelah semua sub-indikator diberi nilai, aset dapat diplot pada matriks (Gambar 1) untuk menentukan letak aset warisan budaya di matriks dan kategori aset warisan budaya.

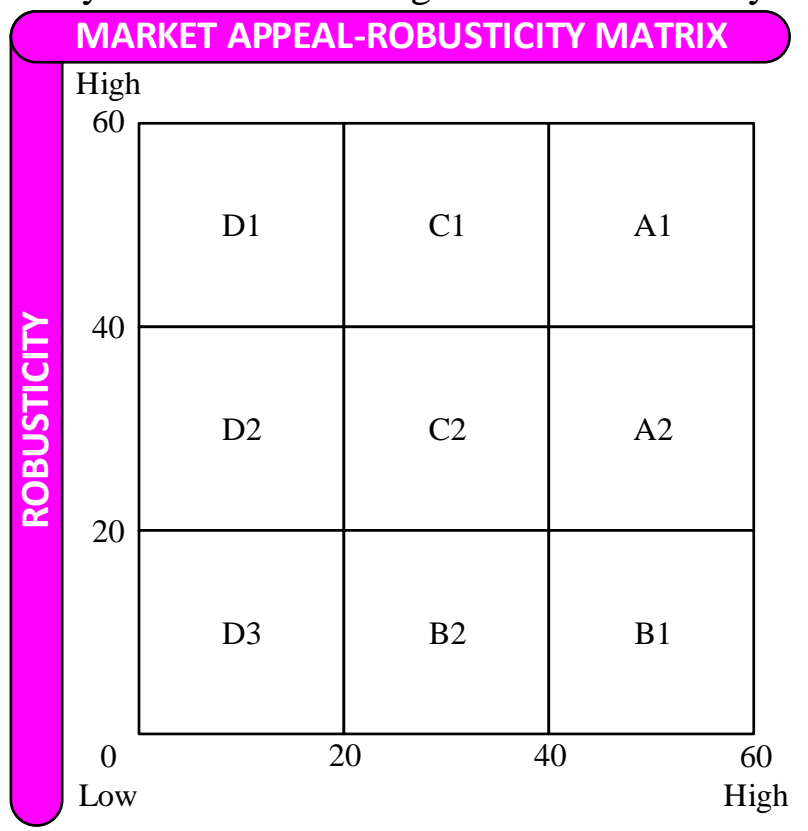

Gambar 1. Market Appeal-Robusticity

Matrix potensi pariwisata

Sumber: du Cros dan McKercher (2015)

Operasionalisasi melibatkan dua langkah: audit sekuensial awal menggunakan masing-masing dimensi secara terpisah dan tinjauan integratif yang menggabungkan semua set nilai. Klasifikasi kategori aset warisan budaya dibagi menjadi empat.

A1 dan A2 merupakan daya tarik pasar yang tinggi dan ketahanan yang tinggi hingga sedang, ideal untuk kegiatan pariwisata yang signifikan karena memiliki fitur untuk menarik wisatawan dan dapat bertahan dalam penggunaan pada tingkat yang signifikan.

B1 dan B2 mewakili daya tarik pasar yang tinggi hingga sedang tetapi rendah dalam ketahanan sehingga pendekatan manajemen adalah untuk memastikan bahwa kunjungan tidak akan merusak nilai-nilai budaya aset. Ketahanannya rendah menunjukkan struktur fisik aset rapuh atau bahwa nilai budayanya sangat sensitif terhadap dampak signifikan dari pengunjung yang datang. Wisatawan mungkin menunjukkan minat yang kuat untuk mengunjungi tempat-tempat ini, tetapi karena aset rapuh maka kemampuannya terbatas untuk mengatasi tingkat kunjungan.
$\mathrm{C} 1$ dan $\mathrm{C} 2$ mewakili ketahanan tinggi hingga sedang tetapi daya tarik pasar sedang. Karena aset dalam kategori ini kuat, aset mungkin dapat menahan tingkat kunjungan yang lebih besar daripada yang disarankan oleh daya tarik pasar saat ini. Oleh karena itu daya tarik pasar dari aset warisan harus dioptimalkan, serta program konservasi dan manajemen pengunjung juga diberlakukan.

D1, D2 dan D3 merupakan daya tarik pasar yang rendah menandakan bahwa aset tidak mungkin menarik kunjungan yang signifikan kecuali aset diubah sedemikian rupa sehingga nilai intrinsiknya akan hampir sepenuhnya dikorbankan. Jenis aset ini harus dikelola untuk beberapa alasan selain pariwisata. Tantangan terbesarnya adalah meyakinkan pengelola aset tentang daya tarik mereka yang terbatas. Dengan menerapkan sistem penilaian ini, peneliti berharap untuk mencapai penyelidikan komprehensif potensi wisata dari aset warisan.

Untuk memeriksa keabsahan data dalam penelitian ini, peneliti menggunakan teknik triangulasi yang dapat diartikan sebagai pengecekan data dari berbagai sumber dengan menggunakan berbagai cara dan waktu (Sugiyono 2014). Dalam triangulasi ini, penulis menggunakan 2 triangulasi; triangulasi sumber dan triangulasi teknik.

\section{HASIL PEMBAHASAN}

Museum Wayang (Gambar 2) terletak di jalan pintu besar utara no. 27-29, Pinangsia, Tamansari, Jakarta Barat, DKI Jakarta. Museum Wayang memamerkan koleksi wayang didapat dari pengadaan, hibah dan titipan. Selain memamerkan koleksi wayang tersebut, Museum Wayang juga menyediakan ruang pagelaran yang menampilkan pertunjukan wayang yang biasanya dilaksanakan setiap hari minggu pukul 10.0014.00 dengan tema pertunjukan berbeda disetiap jadwalnya. Pengunjung dapat menikmati pagelaran dengan tidak dipungut biaya tambahan. Selain ruang pagelaran Museum Wayang juga menyediakan ruang $3 \mathrm{D}$ dimana pengunjung dapat menikmati animasi wayang yang telah disediakan. Pengunjung juga dapat merasakan pengalaman membuat wayang dengan membeli paket workshop yang disediakan untuk rombongan. Hingga saat ini kapasitas bangunan Museum Wayang diperkirakan dapat menampung 300-500 pengunjung perhari. 


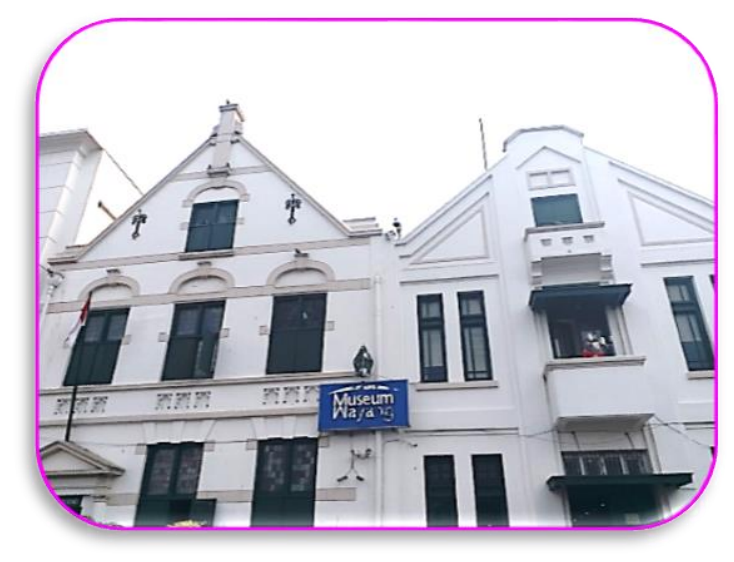

Gambar 2. Museum Wayang Sumber: Peneliti 2019

\section{Pelestarian Warisan Budaya di Museum Wayang}

Pelestarian bangunan Museum Wayang di kelola oleh Pusat Konservasi Cagar budaya. Bangunan Museum Wayang ditetapkan sebagai cagar budaya sesuai dengan keputusan gubernur nomor 475 tahun 1993. Sebagai bangunan cagar budaya, kegiatan pelestarian bangunan Museum Wayang harus sesuai dengan Undang-Undang nomor 11 tahun 2010 tentang Cagar Budaya dan peraturan lain yang terkait. Dalam pelestarian, terdapat tiga aspek yang perlu diperhatikan menurut Rahardjo (2013) yaitu perlindungan, pengembangan dan pemanfaatan.

Perlindungan bangunan Museum Wayang dilakukan untuk mencegah dan menanggulangi bangunan dari kerusakan, kehancuran dan kemusnahan melalui perawatan rutin seperti renovasi pada atap karena bocor, perbaikan eternit, dan pembersihan ruang tata pamer. Pada tahun 2012 bangunan Museum Wayang juga di renovasi, karena Museum Wayang berdiri di dua bangunan maka renovasi dilakukan secara bergantian. Selain itu dilakukan juga zonasi atau pembatasan terhadap wisatawan untuk tidak secara sembarangan menyentuh bangunan yang dapat mengakibatkan kerapuhan dan kerusakan bangunan. Perlindungan juga dilakukan dengan pemasangan papan larangan atau simbol larangan.

Konservasi juga dilakukan pada lantai bangunan Museum Wayang di lantai dua yang menggunakan kayu karena telah rapuh dimakan usia. Pemilihan kayu dilakukan oleh tim ahli cagar budaya sesuai dengan ketentuan yang telah berlaku.
Selain konservasi, Museum Wayang juga mengalami pemugaran bangunan yang dilakukan pada tahun 2005 ketika Museum Wayang mendapatkan hibah bangunan dari Probo Sutejo pemilik PT. Mercu Buana. Dari hasil hibah tersebut, bangunan dipugar dan disesuaikan dengan bangunan lama dengan tidak menghilangkan keaslian bangunan. Selanjutnya bangunan baru pada lantai satu difungsikan sebagai ruang pagelaran, toilet, toko cinderamata. Sedangkan dilantai dua difungsikan sebagai kantor pengelola dan ruang tata pamer.

Sedangkan pengembangan bangunan dilakukan dengan menjadikan bangunan sebagai Museum. Dengan dijadikannya bangunan sebagai Museum maka terdapat peningkatan potensi nilai seperti nilai keindahan, nilai sosial, nilai pendidikan dan nilai ilmiah serta peningkatan informasi melalui dokumen atau data yang dimiliki Museum Wayang. Promosi terhadap bangunan dilakukan dengan atas nama Museum Wayang. Dimana pengelola melakukan promosi menggunakan media sosial dan media cetak seperti brosur dan melalui pameran-pameran.

Dalam pengembangan bangunan, dilakukan pula revitalisasi dengan penyesuaian ruangan bangunan sebagai ruang tata pamer koleksi, ruang pagelaran, ruang $3 \mathrm{D}$, ruang kantor, ruang konservasi dan beberapa ruang disesuaikan untuk dijadikan sebagai fasilitas pendukung seperti mushola. Revitalisasi dilakukan sesuai dengan aturan Peraturan Menteri Pekerjaan Umum Dan Perumahan Rakyat nomor 1 tahun 2015 pasal 16.

Lalu pemanfaatan bangunan Museum Wayang sejak pertama dibangun tahun 1640 dimanfaatkan sebagai gereja, pada tahun 1939 dimanfaatkan sebagai Museum Batavia dan berganti nama menjadi Museum Jakarta pada tahun 1957 hingga pada tahun 1975 dimanfaatkan sebagai Museum Wayang yang berdasarkan Surat Keputusan Gubernur Propinsi DKI Jakarta Nomor 134 tahun 2002 Museum Wayang merupakan Unit Pelaksana Teknis Dinas Kebudayaan dan Permuseuman di bidang pewayangan. Pemanfaatan bangunan sebagai Museum difungsikan sebagai sarana edukasi untuk publik melalui pameran koleksi wayang, dan pagelaran wayang. Selain sebagai sarana edukasi, bangunan Museum 
Wayang juga dapat dimanfaatkan oleh masyarakat untuk kegiatan lain seperti syuting ataupun pemotretan dengan ketentuan yang diatur dalam Peraturan Daerah nomor 1 tahun 2015 tentang Tarif Retribusi Pelayanan Kebudayaan dan Permuseuman.

\section{Penilaian Aset Warisan Budaya Museum Wayang}

Penilaian aset warisan budaya yang dibagi menjadi dua bagian, yang pertama adalah sektor pariwisata yang didalamnya terdapat penilaian terhadap Market Appeal (daya tarik pasar), dan Product design needs (nilai pariwisata) atraksi wisata budaya Museum Wayang dan penilaian kedua mengenai pengelolaan warisan budaya yang didalamnya terdapat penilaian terhadap Cultural Significance (nilai budaya) dan Robusticity (nilai fisik) yang terkait dengan bangunan. Hasil penilaian didapat melalui pernyataan-pernyataan yang dipilih responden yang dirasa sesuai dengan pengalaman yang telah didapat responden dari hasil kunjungannya ke Museum Wayang.

Hasil penilaian diolah menggunakan rumus konversi ordinal ke interval untuk menentukan pembobotan nilai market appeal-robusticity matrix Sektor Pariwisata Museum Wayang (Tabel 2) dan pembobotan nilai market appealrobusticity matrix Pengelolaan Warisan Budaya Museum Wayang (tabel 3). Berikut adalah hasil pembobotannya.

Tabel 2. Pembobotan nilai market appeal-robusticity matrix Sektor Pariwisata Museum Wayang

\begin{tabular}{|l|c|}
\hline \multicolumn{1}{|c|}{ Indikator sektor pariwisata } & $\begin{array}{c}\text { Nilai } \\
\text { Museum } \\
\text { Wayang }\end{array}$ \\
\hline \hline Suasana dan keadaan & 4 \\
\hline Terkenal di luar daerah setempat & 4 \\
\hline Ikon nasional atau Simbol nasional & 4 \\
\hline Menceritakan sebuah kisah yang bagus & 4 \\
\hline $\begin{array}{l}\text { Memiliki ciri khas yang membedakannya } \\
\text { dari atraksi disekitar Kawasan Kotatua }\end{array}$ & 4 \\
\hline $\begin{array}{l}\text { Menawarkan kegiatan khusus yang juga } \\
\text { menarik (seperti festival, olahraga, workshop) }\end{array}$ & 4 \\
\hline $\begin{array}{l}\text { Melengkapi atraksi wisata lain disekitar } \\
\text { Kawasan Kotatua }\end{array}$ & 4 \\
\hline $\begin{array}{l}\text { Merupakan aset warisan budaya yang penting } \\
\text { secara lokal, regional, nasional, atau } \\
\text { internasional }\end{array}$ & 5 \\
\hline Menggambarkan keunikan suatu tradisi budaya & 5 \\
\hline $\begin{array}{l}\text { Tersedianya informasi yang sesuai dan } \\
\text { memadai }\end{array}$ & 4 \\
\hline
\end{tabular}

\begin{tabular}{|l|c|}
\hline \multicolumn{1}{|c|}{ Indikator sektor pariwisata } & $\begin{array}{c}\text { Nilai } \\
\text { Museum } \\
\text { Wayang }\end{array}$ \\
\hline $\begin{array}{l}\text { Dapat diakses dengan mudah menggunakan } \\
\text { transportasi }\end{array}$ & 3 \\
\hline Dekat dengan atraksi wisata budaya yang lain & 2 \\
\hline $\begin{array}{l}\text { Keadaan amenitas (fasilitas) yang ada di } \\
\text { Museum Wayang, termasuk toilet, parkir, } \\
\text { jalur, mushola }\end{array}$ & 4 \\
\hline \hline \multicolumn{1}{|c|}{ TOTAL } & $\mathbf{5 1}$ \\
\hline
\end{tabular}

Sumber: Peneliti 2019

Tabel 3. Pembobotan nilai market appealrobusticity matrix Pengelolaan Warisan Budaya Museum Wayang

\begin{tabular}{|c|c|}
\hline Indikator Pengelolaan Warisan Budaya & $\begin{array}{c}\text { Nilai } \\
\text { Museum } \\
\text { Wayang }\end{array}$ \\
\hline $\begin{array}{l}\text { Nilai keindahan (termasuk nilai arsitektur } \\
\text { dalam hal bangunan) }\end{array}$ & 1 \\
\hline Nilai historis/sejarah & 1 \\
\hline Nilai pendidikan & 1 \\
\hline Nilai sosial & 1 \\
\hline Nilai ilmiah/adanya potensi penelitian & 1 \\
\hline $\begin{array}{l}\text { Jenis aset warisan budaya yang langka atau } \\
\text { umum di tempat tujuan }\end{array}$ & 2 \\
\hline $\begin{array}{l}\text { Aset warisan budaya menjadi contoh wisata } \\
\text { warisan budaya yang baik di Kawasan Kotatua }\end{array}$ & 4 \\
\hline Kondisi kerapuhan bangunan & 3 \\
\hline Kondisi perbaikan bangunan & 3 \\
\hline $\begin{array}{l}\text { Perencanaan pengelolaan dan kebijakan } \\
\text { yang berlaku }\end{array}$ & 3 \\
\hline $\begin{array}{l}\text { Pemantauan dan pemeliharaan (perawatan) } \\
\text { rutin bangunan }\end{array}$ & 4 \\
\hline $\begin{array}{l}\text { Adanya potensi kerjasama berkelanjutan } \\
\text { para pengelola }\end{array}$ & 4 \\
\hline $\begin{array}{l}\text { Adanya kemungkinan dampak negatif } \\
\text { (karena kunjungan yang tinggi) terhadap: }\end{array}$ & \\
\hline a. Struktur bangunan & 3 \\
\hline \begin{tabular}{|l|} 
b. Gaya hidup dan tradisi budaya masyarakat \\
setempat
\end{tabular} & 3 \\
\hline $\begin{array}{l}\text { Adanya kemungkinan dampak negatif } \\
\text { (karena perubahan dalam pengembangan) pada: }\end{array}$ & \\
\hline a. Struktur bangunan & 3 \\
\hline \begin{tabular}{|l} 
b. Gaya hidup dan tradisi budaya \\
masyarakat setempat
\end{tabular} & 3 \\
\hline TOTAL & 40 \\
\hline
\end{tabular}

Sumber: Peneliti 2019

Hasil pembobotan nilai market appeal-robusticity matrix pada sektor pariwisata menghasilkan total 51 poin, menandakan bahwa sektor pariwisata Museum Wayang tinggi dan pada sektor pengelolaan warisan budaya menghasilkan 
total 40 poin, menandakan bahwa pengelolaan warisan budaya Museum Wayang sedang. Selanjutnya hasil poin di plot dalam matriks. Dapat dilihat pada Gambar 3 sebagai berikut.

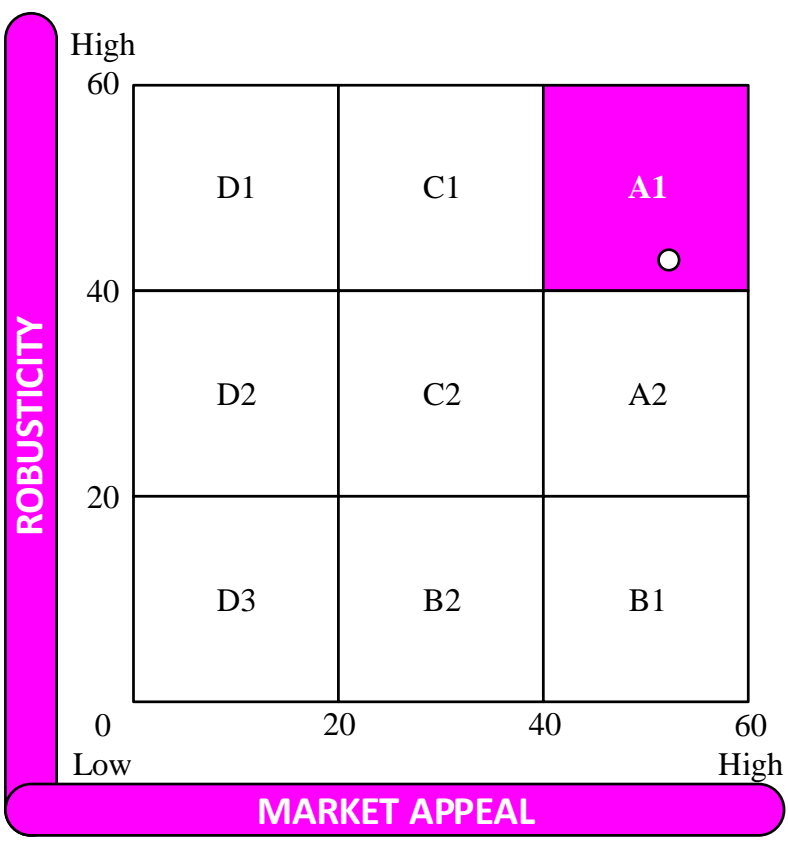

Gambar 3 Market Appeal-Robusticity Matrix

Museum Wayang (Sumber: Peneliti 2019)

Dari hasil plot matriks tersebut Museum Wayang masuk ke kategori "A1". Hal ini menandakan bahwa daya tarik pasar Museum Wayang bernilai tinggi dan ketahanan Museum Wayang yang bernilai sedang sehingga Museum Wayang sangat ideal untuk kegiatan pariwisata yang signifikan karena Museum Wayang dapat menarik wisatawan dan untuk ketahanan bangunan, menurut Pengelola Museum Wayang (2019), saat ini dinilai cukup mampu menampung jumlah kunjungan wisatawan yang signifikan.

\section{KESIMPULAN DAN SARAN}

Bangunan Museum Wayang didirikan pada tahun 1640 telah beberapa kali berganti pemanfataan atau fungsi bangunan hingga akhirnya dinyatakan sebagai bangunan cagar budaya berdasarkan SK Gubernur Nomor 475 Tahun 1993 dan dijadikan sebagai Museum Wayang pada tahun 1975. Dalam pelestariannya terdapat terdapat tiga unsur yang diperhatika yaitu, unsur perlindungan, pengembangan dan pemanfaatan (Raharjo, 2013). perlindungan di Museum
Wayang ialah perawatan rutin dan pemeliharaan struktur bangunan melalui renovasi bangunan, konservasi dan pemugaran serta dilakuakan kontrol secara berkala oleh tenaga ahli cagar budaya. Pada unsur kedua, pengembangan, bangunan yang kini menjadi Museum Wayang mengandung banyak nilai yang tinggi seperti nilai keindahan bangunan, nilai sosial yang terkandung di bangunan, nilai pendidikan melalui sejarah yang terkandung dan nilai ilmiah yang menjadikan bangunan berpotensi untuk dijadikan sebagai tempat penelitian. Selain peningkatan nilai, informasi dan promosi bangunan juga meningkat karena bangunan yang kini dijadikan sebagai Museum Wayang. Dan pada unsur ketiga pelestarian, pemanfaatan, bangunan cagar budaya Museum Wayang sejak awal dibangun selalu dimanfaatkan untuk kesejahteraan rakyat seperti digunakan sebagai gereja, digunakan sebagai gudang penyimpanan, dan digunakan sebagai Museum yang merupakan sarana edukasi untuk publik.

Mengenai penilaian aset warisan budaya di Museum Wayang, didapatkan hasil skor penilaian terhadap daya tarik sebesar 51 dan penilaian terhadap ketahanan Museum Wayang yaitu sebesar 40. Setelah diplot pada matriks Market appeal dan robusticity, Museum Wayang berada di kategori "A1" yang artinya daya tarik di Museum Wayang tinggi memiliki daya tarik pasar yang tinggi dan dapat menarik wisatawan untuk berkunjung secara signifikan dan ketahanannya sedang dimana Museum Wayang cukup kuat dapat menghadapi kunjungan wisatawan yang signifikan.

Dalam hal pelestarian di Museum Wayang, pengelola agar memperhatikan setiap unsur terlaksana dengan baik sesuai dengan peraturan yang berlaku. Seperti halnya perawatan fasilitas agar lebih diperhatikan dengan baik. Dalam hal pengembangan, penyajian informasi agar diperbaiki dan disesuaikan karena penyediaan informasi masih belum sesuai dengan peraturan yang berlaku dan perbaikan website resmi Museum Wayang juga diperlukan untuk menunjang kegiatan promosi.

Berdasarkan hasil penilaian aset warisan budaya (tabel 4.2), ketahanan bangunan dinilai sedang atau cukup mampu dalam menampung kunjungan wisatawan secara signifikan. Bangunan Museum Wayang yang merupakan bangunan 
cagar budaya tentu harus diperhatikan kerapuhannya. Untuk menghindari kemungkinan dampak negatif yang ditimbulkan dengan adanya kunjungan wisatawan yang tinggi, maka sebaiknya pengelola menetapkan suatu kebijakan terhadap pengelolaan pengunjung mengenai batas daya tampung (carrying capacity) Museum Wayang. Untuk melindungi bangunan Museum Wayang agar tidak cepat rapuh dan menghindari kecelakaan yang mungkin dapat membahayakan pengunjung karena kerapuhan bangunan.

\section{UCAPAN TERIMAKASIH}

Penelitian ini terlaksana dengan baik karena adanya kerjasama dari Unit Pengelola Museum Wayang dan Unit Pengelola Kotatua yang memudahkan peneliti dalam melaksanakan penelitian dan membantu pengumpulan data. Serta pengunjung Museum Wayang yang berpartisipasi dalam pengisian kuesioner penelitian ini.

\section{DAFTAR PUSTAKA}

Ambrose T, Paine C. 2005. Museum Basics. New York (US): Routledge

Ambrose T, Paine C. 2006. Museum Basics (second edition). New York (US): Routledge Anggito A, Setiawan J. 2018. Metodelogi Penelitian Kualitatif. Sukabumi (ID): Jejak.

Ardiwidjaja R. 2018. Arkeowisata: Mengembangkan Daya Tarik Pelestarian Warisan Budaya. Yogyakarta (ID): Deepublish

Arikunto S. 2006. Prosedur Penlitian Suatu Pendekatan Praktik. Jakarta (ID): Rineka Cipta Badan Pusat Statistik. 2019. Jumlah kunjungan wisman ke Indonesia Desember 2018 mencapai 1,41 juta kunjungan. Diakses pada pukul 18.49 tanggal 17 juli 2019 https://www.bps.go.id/ pressrelease/2019/02/01/1543/jumlah

Davison G, McConville C. 1991. A Heritage Handbook. New South Wales (AUS): Allen \& Unwin.

Druvaskalne ID, Livina A. 2008. Sustainable Tourism Development on the Basis of Cultural Heritage in North Vidzeme Biosphere Reserve, Latvia. Latvia (LV): Universitas Vidzeme

du Cros H, McKercher B. 2015. Cultural Tourism (second edition). New York (US): Routledge du Cros H. 2001. A New Model to Assist in Planning for Sustainable Cultural Heritage Tourism. Intenational Journal of Tourism Research, 3

Fitrah M, Luthfiyah. 2017. Metodelogi penelitian: Penelitian Kualitatif, Tindakan Kelas Dan Studi Kasus. Sukabumi (ID): Jejak

Fitriansah N. 2014. Analisis Pengembangan Aplikasi Jelajah Museum Jogja Berbasis Android. Skripsi. Universitas Negeri Yogyakarta.

Hadiyanta E. 2017. Dinamika Pelestarian Cagar Budaya. Yogyakarta (ID): Penerbit Ombak.

Hermawan A. 2005. Penelitian Bisnis Paradigma Kuantitatif. Jakarta (ID): Grasindo.

Hermawan H, Hendrastomo G. 2017. Traveling Sebagai Gaya Hidup Mahasiswa Yogyakarta. Jurnal Sosiologi (1)

International Council of Museums. Pengertian Museum. Diakses pada 5 April 2018. Pukul 20:42.https://icom.museum/en/activities/sta ndards-guidelines/standards/

Kausar DRK. 2013. Warisan Budaya, Pariwisata dan Pembangunan di Muarajambi, Sumatra. Journal of Tourism Destination and Attraction, $1(1)$

Kausar DRK. 2017. Perencanaan dan pengelolaan pariwisata budaya. Bahan Perkuliahan -kunjungan-wisman-ke-indonesia-desember2018-mencapai-1-41-juta-kunjungan.html

Kusherdyana. 2011. Pemahaman Lintas Budaya: dalam Konteks Pariwisata dan Hospitalitas. Bandung (ID): Alfabeta

Li Y, Lo RLB. 2004. Applicability Of The Market Appeal-Robusticity Matrix: A Case Study Of Heritage Tourism. Tourism Management 25 (2004)

Machmud M. 2016. Tuntutan Penelitian Tugas Akhir Berdasarkan Prinsip Dasar Penelitian Ilmiah. Malang (ID): Penerbit Selaras

Martoatmodjo K. 2014. Pelestarian Bahan Pustaka. Modul 1. Prosiding

Moleong LJ. 2000. Metodologi Penelitian Kualitatif. Bandung (ID): Remaja Rosdakarya

Pendit NS. 2003. Ilmu Pariwisata (Sebuah Pengantar Perdana). Jakarta (ID): Pradnya paramita

Peraturan Daerah nomor 1 tahun 2015 tentang Tarif Retribusi Pelayanan Kebudayaan dan Permuseuman 
Peraturan Menteri Kebudayaan dan Pariwisata nomor 45 tahun 2009 tentang Pedoman Permuseuman

Peraturan Menteri Pekerjaan Umum Dan Perumahan Rakyat nomor 1 tahun 2015 tentang Bangunan Gedung Cagar Budaya Yang Dilestarikan

Peraturan Pemerintah Republik Indonesia Nomor 19 Tahun 1995 Tentang Museum.

Pitana IG, Diarta IKS. 2009. Pengantar Ilmu Pariwisata. Yogyakarta (ID): Penerbit Andi

Raco. 2010. Metode penelitian kualitatif. Jakarta (ID): Grasindo

Rahardjo S. 2013. Beberapa Permasalahan Pelestarian Kawasan Cagar Budaya Dan Strategi Solusinya. Jurnal Konservasi Cagar Budaya Borobudur, 7 (2),

Rapidah MS, Mohamed KR, Ali CA, Leman MS, Saidin M. 2018. The Application Of Market Appeal-Robusticity Matrix: A Case Study Of The Archaeological Heritage Of Lenggong Valley, Perak, Malaysia. GeoJournal of Tourism and Geosites, 23(3),

Spillane JJ. 1987. Ekonomi pariwisata, Sejarah dan Prospeknya. Yogyakarta (ID): Kanisius

Stamenković I, Jakšić S. 2013. Tourism Potential Valorisation Of The Old Town Centre In Sombor Based On The Hilary Du Cros Model. European Researcher, (53)
Stanojlović A, Curčić N, Pavlović N. 2010. Tourism Valorisation Of Site "Lazar's Town" In Kruševac. Geographical Institute "Jovan Cvijić” Sasa, 60 (2)

Sugiarto E. 2017. Menyusun Proposal Penelitian Kualitatif: Skripsi dan Tesis. Yogyakarta (ID): Suaka Media.

Sugiyono. 2014. Metode Penelitian Kuanititatif, Kualitatif dan R\&D. Bandung (ID): Alfabeta Sutaarga A. 1997. Pedoman Penyelenggaraan dan Penelolaan Museum. Jakarta (ID): Departemen Pendidikan dan Kebudayaan Direktoral Jendral Kebudayaan Proyek Pembinaa Permuseuman

Tanudirjo DA. 2004. Pengelolaan Sumber Daya Arkeologi: Sebuah Pengantar. Yogyakarta (ID): Universitas Gajah Mada.

Tela IN. 2017. Penilaian Aset Warisan Budaya Minangkabau Sebagai Tonggak Pelancongan Warisan Di Kabupaten Tanah Datar, Indonesia. Tesis. Universitas Teknologi Malaysia Undang-Undang Republik Indonesia Nomor 11 Tahun 2010 Tentang Cagar Budaya

Waluyo B. 2007. Sosiologi: Menyelami Fenomena Sosial Di Masyarakat. Bandung (ID): Setia Purna Inves

Yoeti OA. 2006. Pariwisata Budaya: Masalah dan Solusinya. Jakarta (ID): Pradnya paramita. 